\title{
ПРОБЛЕМЫ ПЕРЕДВИЖЕНИЯ МАЛОМОБИЛЬНЫХ ГРУПП НАСЕЛЕНИЯ В ГОРОДЕ ДНЕПР
}

\author{
к.т.н., доцент Саньков Петр Николаевич \\ к.т.н., доцент Кислица Лина Викторовна \\ к.т.н., дочент Капшук Ольга Анатольевна
} Украина, г. Днепр, ГВУЗ Приднепровская государственная академия Строительства и
Архитектуры

DOI: https://doi.org/10.31435/rsglobal_ejits/31072019/6582

\section{ARTICLE INFO}

Received 24 May 2019

Accepted 19 July 2019

Published 31 July 2019

\section{KEYWORDS}

people with disabilities, people with limited mobility, ramps, access roads.

\begin{abstract}
The purpose of the study was to analyze the city of Dnepr for the suitability of movement of people with limited mobility. The need to create an accessible environment for the movement of people with disabilities and people with limited mobility. The main problem faced by these people is the inaccessibility of the living environment, namely, education, employment and communication. Considered the central streets of the city. Movement problems on footpaths and entrances to buildings were identified. The basic requirements for footpaths and their adaptation to people with limited mobility are given. Proposed solutions to the problems of communication for people with disabilities. The need to comply with the requirements of building codes for functional planning elements of buildings, and especially of communication between them.
\end{abstract}

Citation: Саньков П. Н., Кислица Л. В., Капшук О. А. (2019) Problemy Peredvizheniya Malomobil'nyh Grupp Naseleniya v Gorode Dnepr. European Journal of Intelligent Transportation Systems. 1(2). doi: $10.31435 /$ rsglobal_ejits/31072019/6582.

Copyright: () 2019 Саньков П. Н., Кислица Л. В., Капшук О. А. This is an open-access article distributed under the terms of the Creative Commons Attribution License (CC BY). The use, distribution or reproduction in other forums is permitted, provided the original author(s) or licensor are credited and that the original publication in this journal is cited, in accordance with accepted academic practice. No use, distribution or reproduction is permitted which does not comply with these terms.

Введение. Статистика неумолима: за последние 10 лет количество людей, страдающих от нарушений нормальной деятельности опорно-двигательной системы, возросло во многих странах мира на 25-35\%. Украина - не исключение. Если ситуация не стабилизируется, до 2020 года нарушения функций опорно-двигательного аппарата и позвоночника выйдут на 1 место в мире по распространенности, опередив даже сердечно-сосудистые заболевания [1].

Генеральной Ассамблеей ООН 13-го декабря 2006 года была принята Конвенция ООН о правах инвалидов [2], которая является международным договором в области прав человека. Конвенция вступила в силу 3 мая 2008 года после ее ратификации двадцатью государствами участниками. На сегодняшний день более 150 стран и организаций региональной интеграции подписали Конвенцию, из них свыше 130 ее ратифицировали. Также, первого января 2016 г. вступили в силу принятые всеми странами - членами ООН Цели Устойчивого Развития (ЦУР) и Повестка дня в области устойчивого развития на период до 2030 года. Учитывая базовый принцип этих глобальных документов - «никто не будет забыт», включение в Повестку дня 2030 в качестве одной из важнейших целевых групп людей, живущих с инвалидностью, правительствам стран предстоит при принятии решений о национальных стратегиях, направленных на достижение ЦУР, уделять особое внимание дальнейшему совершенствованию программ в интересах людей с инвалидностью» [3].

В Украине примерно $6 \%$ людей с инвалидностью, что составляет около 2,7 млн. жителей страны. Но в соответствии с ДБН В.2.2.-40:2018 [4] к маломобильным группам населения (МГН) 
относятся - люди, которые ощущают трудности с самостоятельным передвижением, получением услуги, необходимой информации или ориентировании в пространстве. К маломобильным группам относят: людей с инвалидностью, с временным нарушением здоровья, беременные женщины, пожилые люди и люди с детскими колясками. Из вышеперечисленного, самой "уязвимой" группой населения являются люди с инвалидностью. Такие люди должны жить полноценно. Немаловажную роль в этом играют условия и возможности передвижения людей по городу.

Цель исследования: анализ проблем передвижения маломобильных групп населения.

Необходимость формирования доступной среды для передвижения людей с инвалидностью и МГН является основным направлением социальной политики. Результаты этого, должны обеспечить равные возможности для всех групп населения.

Главной проблемой, с которой сталкиваются МГН - это недоступность среды жизнедеятельности, а именно, получения образования, трудоустройства, коммуникации.

В нашей стране огромное количество социально-культурных объектов. Вместе с ними необходимыми являются магазины, аптеки, государственные учреждения, к которым доступа без посторонней помощи маломобильному населению нет.

Большинство этих сооружений и пути следования к ним не адаптированы для людей с инвалидностью.

На примере г. Днепра были рассмотрены центральные улицы города, а также транспортное сообщение с ними (рис.1-3).
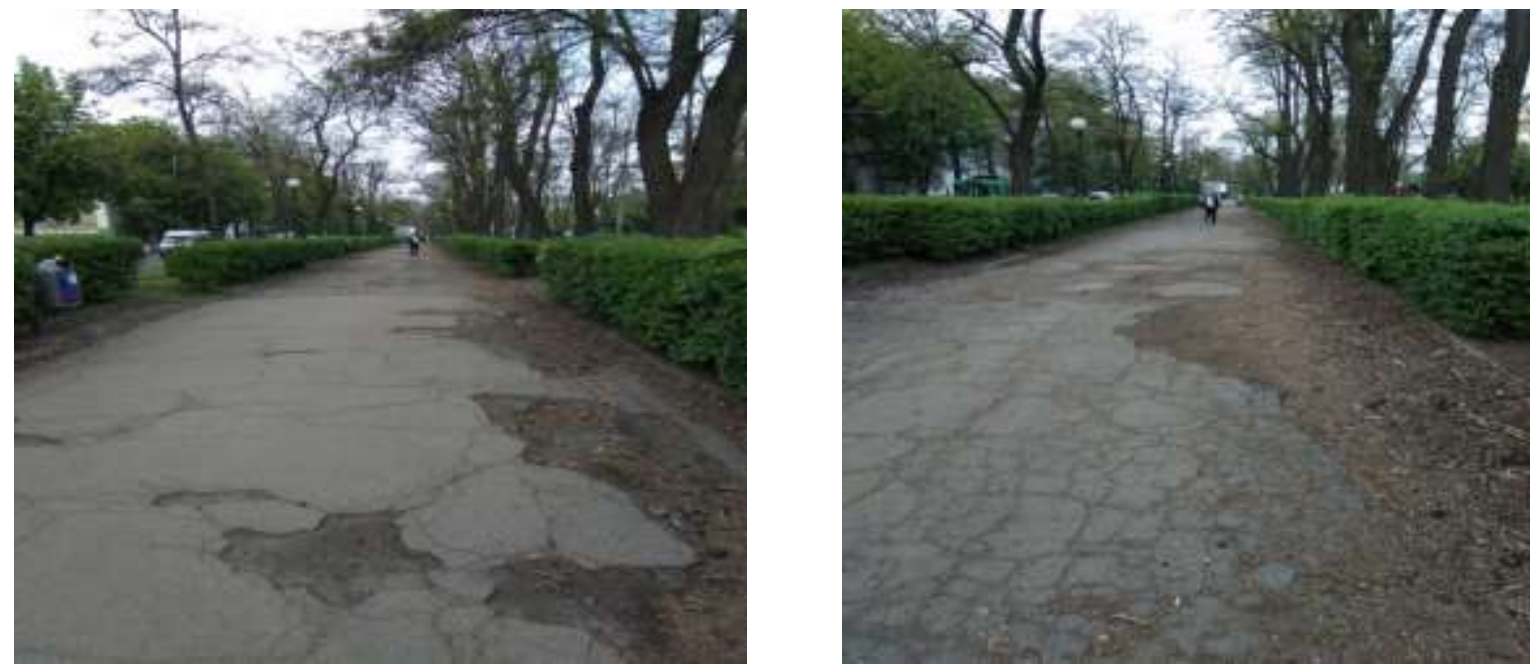

Рис. 1. Центральная аллея г. Днепр (пр. Д. Яворницкого)
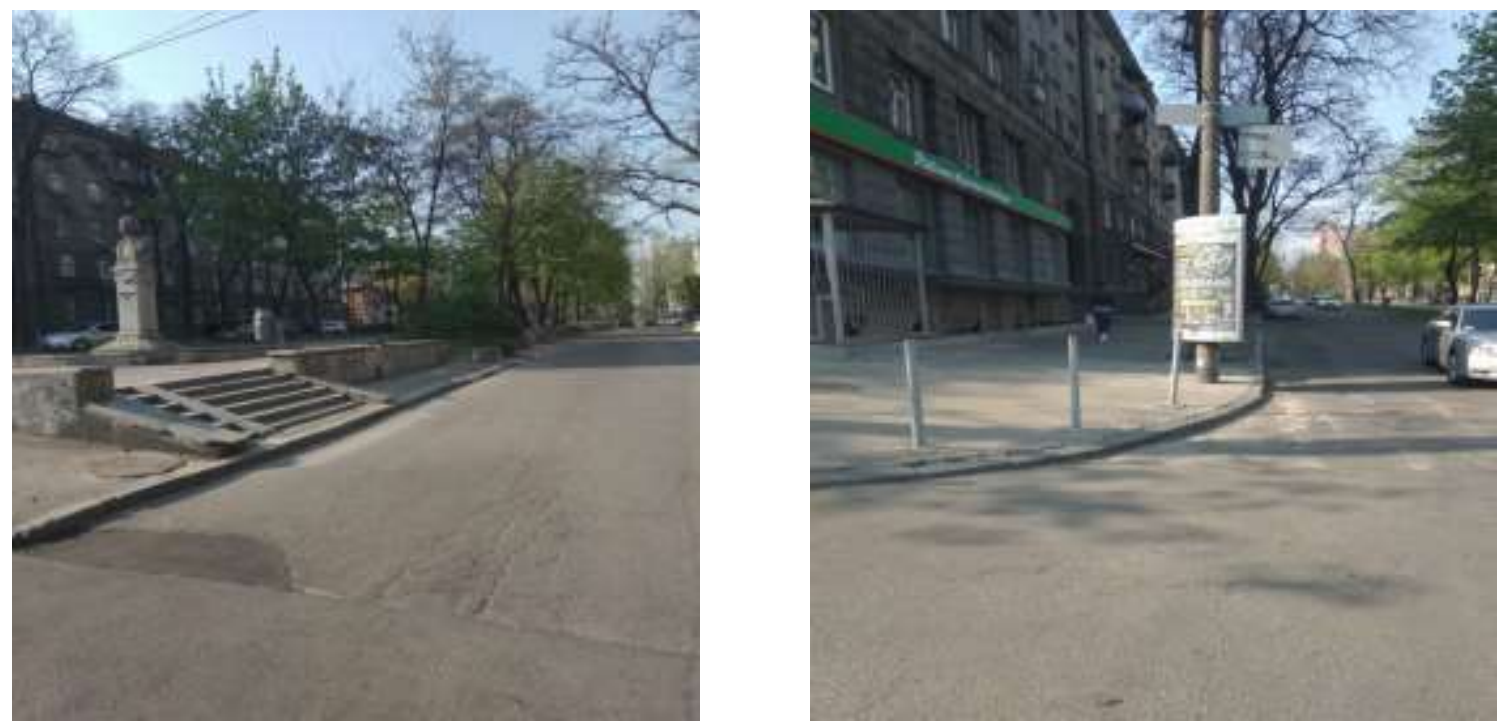

Рис. 2. Центральный проспект города пр. Д. Яворницккого 

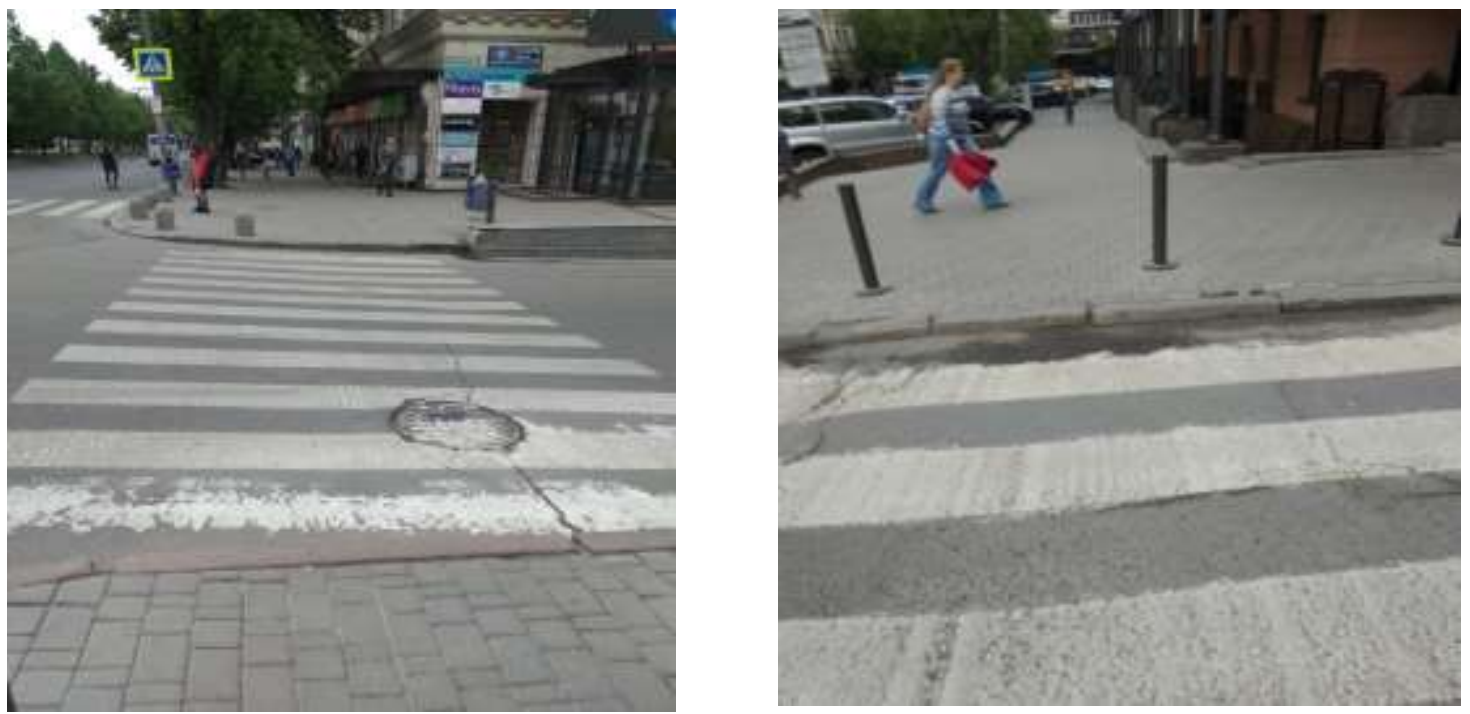

Рис. 3. Один из пешеходных переходов по пр. Д.Яворницкого

Как видим, центральные улицы города находятся в плачевном состоянии. По ним проблематично передвигаться и работоспособным горожанам, не говоря о людях с ограниченными возможностями.

Город строился и расширялся в течении двух столетий. И только в последние 5 лет начали обращать внимание на такие социальные и масштабные проблемы, как свободное передвижение маломобильных слоев населения.

Для обеспечения комфорта передвижения людей с инвалидностью, необходимо чтобы выполнялись требования строительных норм к функционально-планировочным элементам зданий, а особенно путей сообщения между ними (дорогам, съездам, пешеходным дорожкам и т.д.)

Ниже приведены основные требования, а именно:

- ширина пешеходных дорожек не менее 1,8м;

- для покрытия пешеходных дорожек нельзя использовать насыпные или крупноструктурные материалы, которые могут мешать передвижению на колясках или костылях;

- продольный уклон пешеходных дорог не должен превышать 5\%, если более необходимо устраивать внешние пандусы;

Это лишь малый перечень требований к путям передвижения МГН.

Проведя анализ объектов социально-культурного и образовательного назначения в г. Днепр, а также проездов, тротуаров и детских площадок, выяснилось, что только около $25 \%$ этих объектов пригодны для МГН, но во многих нужна посторонняя помощь для подъема по пандусам. ГВУЗ ПГАСА имеет пандус, но уклон не соответствует самостоятельному передвижению на инвалидных колясках (рис.4).
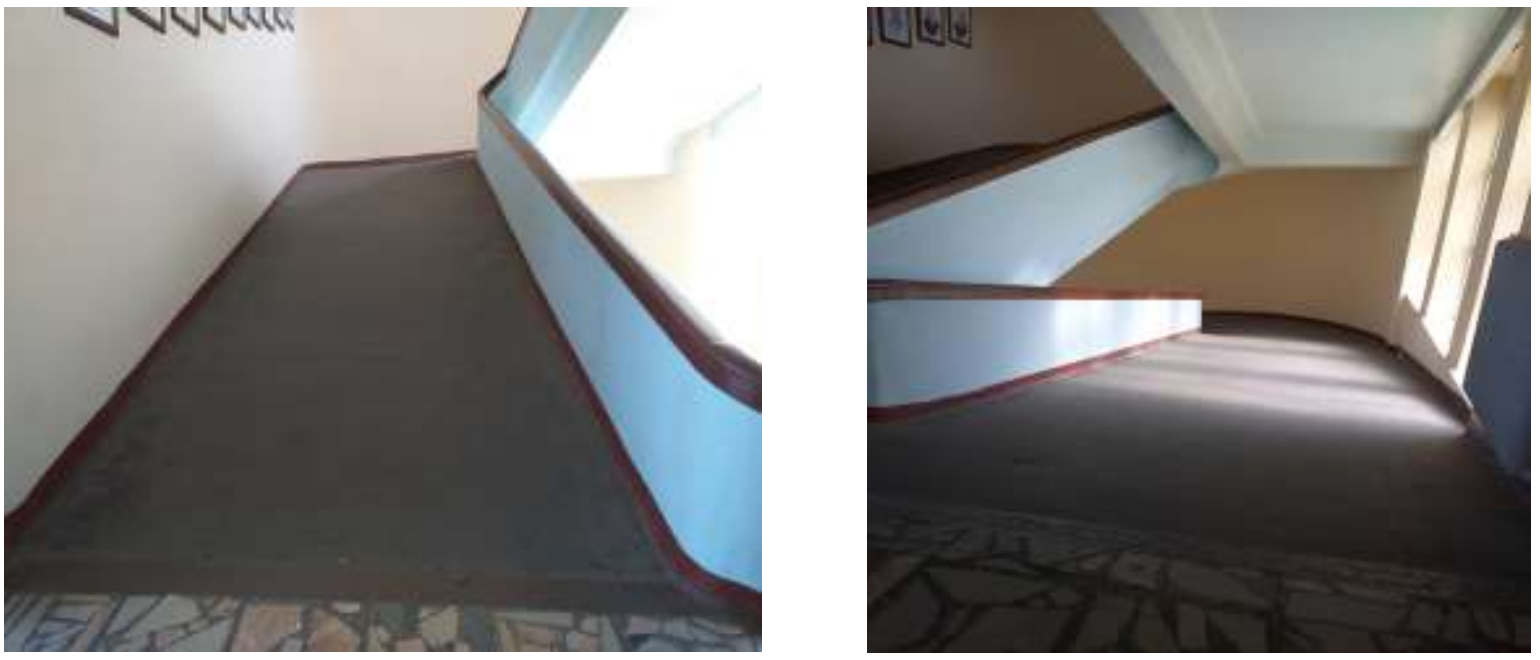

Рис. 4. Пандус внутри ГВУЗ ПГАСА 
Во многих заведениях есть возможность обеспечить доступ людей с инвалидностью на 1 этаж, однако в самом здании это выполнить невозможно по ряду причин. Иногда, возможность строительства пандуса отсутствует из-за перепада отметок или несущих конструкций по строительным нормам.

В соответствии с ДБН В.2.2.-40:2018 к МГН, относится очень много других социальных групп. Следовательно, все, что делается для людей с инвалидностью, будет удобным и для всех остальных жителей города.

Выводы. Для адаптации города Днепр к потребностям МГН необходимо:

- провести анализ доступности зданий для МГН;

- разработка решений по устранению недостатков;

- обустройство подъездных путей и пешеходных дорожек пандусами, подходами (подъездами к зданию).

\section{ЛИТЕРАТУРА}

1. Эектронный ресурс: Телеканал TCH Украины. URL: https://ru.tsn.ua/ukrayina/professor-bubnovskiyrasskazal-o-lechenii-problem-oporno-dvigatelnogo-apparata.html (дата обращения 21.04.2012)

2. Электронный ресурс: Резолюция ГА

URL: https://www.un.org/ru/ga/61/docs/61res_nocte.shtml (дата обращения 05.07.2018)

3. Статистика о жизни людей с инвалидностью в странах Содружества независимых государств; статистический сборник / Межгосударственный статистический комитет СНГ/. - М. 2018. - 52 с.

4. ДБН В.2.2.-40:2018 "Інклюзивність будівель і споруд". / Міністерство регіонального розвитку, будівництва та житлово-комунального господарства України/ Київ, 2018- 99с. 